\title{
Conception of Hollow Axles Forming by Skew Rolling with Moving Mandrel
}

\author{
Zbigniew Pater ${ }^{1 *}$, Patrycja Walczuk-Gągała ${ }^{1}$ \\ 1 Mechanical Faculty, Lublin University of Technology, 36 Nadbystrzycka Str., 20-618 Lublin, Poland \\ * Corresponding author's email: z.pater@pollub.pl
}

\begin{abstract}
The article presents a conception of manufacturing a hollow axle using three skewed rolls moving at the same rotating speed, axially moving chuck and a moving mandrel. The outer shape of the axle is obtained as a result of combining the radial feed of the rolls with axial feed of the chuck. The hole in the axle, however, is obtained as a result of the mandrel acting on the workpiece while moving along with it. In order to assess the correctness of the presented concept of forming, a numerical simulation was performed in Simufact. Forming commercial software. The results of the simulation confirmed that the applied method allows one to manufacture large-size hollow axles. Moreover, information on force parameters of the forming process, which can be used for designing an industrial rolling mill was obtained.
\end{abstract}

Keywords: hollowed axle, skew rolling, FEM.

\section{INTRODUCTION}

Hollow axles and shafts are increasingly common in automation and machine industry, due to the fact that their mechanical properties are comparable to the ones of solid elements, while offering a significantly lower mass. Currently, such elements are manufactured using one of the following methods [1]: machining, metal forming, casting and powder metallurgy.

Metal forming methods are especially popular in the case of manufacturing hollow elements. They are highly effective, allow one to enhance mechanical properties as well as to decrease energy and material consumption of the manufacturing process. Currently, hollow elements are manufactured using the following methods: roll forming, cross-wedge rolling (CWR), forging on swaging machines, hydroforming, extrusion and spinning [1].

Lately, intensive research on new methods of forming large-size axles and shafts, used e.g. in heavy-loaded trucks or railway wagons was carried out. Such elements are most often manufactured by forging on swaging machines [2]. In order to increase forming effectiveness, technology of cross-wedge rolling was examined. The main issue with CWR is the length of the rail axles, reaching $2.5 \mathrm{~m}$. Rolling such elements in the traditional manner would require using rolling mills with the diameter of rolls exceeding $2 \mathrm{~m}$, which is not available on the market.

In order to decrease the length of the tools (decreasing roll diameter) Shu et al. [3] proposed a multi-wedge rolling method, in which the axle is rolled by a few pairs of wedges simultaneously. A drawback of this method in an excessive ovalisation of the cross-section, which may cause the workpiece to axially fracture in the case of whole elements. In order to eliminate this phenomenon Pater and Tomczak [4] proposed a two-stage rolling method. In the first stage, the central part of the axle is formed with one pair of rolls, whereas in the second one another pair of rolls forms side steps of the axle. Such a solution allows one to decrease the nominal diameter of the rolls to an acceptable value, equal $1200 \mathrm{~mm}$. An alternative solution proposed by Pater [5] consisted of introducing 
special undercuts to the calibrating part of the tools, which would reduce excessive ovalisation of the cross-section of the workpiece.

In the case of hollow axles it is necessary to control the inner diameter using a cylindrical mandrel. Its usage, however, facilitates excessive deformation of the cross-section of the workpiece $[6,7]$. An important aspect of designing the CWR process for hollow elements is an accurate choice of the angles of the wedge, mainly the forming angle and spreading angle. On the basis of the analyses performed [8,9] it was stated that in the case of forming hollow elements tools with smaller spreading angle ad greater forming angle ought to be used. Lately, studies $[10,11]$ indicating the validity of employing three rolls in skew rolling processes of hollow elements. In this type of rolling, deformations of the cross-section of the workpiece is significantly smaller than in the case of two-roll rolling. These conclusions, however, are based purely on theoretical considerations.

The lately developed method of skew rolling in a CNC rolling mill seems promising in terms of forming long stepped axles and shafts. This method is highly universal. The same set of three rolls allows one to manufacture axial-symmetric elements of various shape $[12,13]$. This indicates that this method can be used in small-scale production. The first attempts at rolling full rail axles in 1:5 scale in laboratory conditions confirmed another benefit of this process, that is relatively small (compared to the dimensions of the workpiece) values of forming forces and torque. This results in small energy consumption of the manufacturing process as well as light construction of the rolling mill. The latest numerical analyses $[16,17]$ indicated that this method would allow one to manufacture hollow rail axles.

This paper presents a new concept of skew rolling large-size hollow axles in a CNC rolling mill. The innovation of this solution is the usage of a moving mandrel, which influences the inner diameter of the workpiece. The correctness of the assumed forming concept was proven using a numerical simulation.

\section{THE PRINCIPLE OF THE PROPOSED FORMING PROCESS AND ITS NUMERICAL MODEL}

The innovative method of forming hollow elements was presented using the example of an axle shown in Figure 1. It is a rail axle with a cylindrical hole with a $\varnothing 80 \mathrm{~mm}$ diameter. For the rolled axle, two technological allowances were assumed. One of those is linked to fastening the billet in the chuck, whereas the other is connected to the rolls leaving the forming zone. The allowances shall be removed from the axle after the forming process.

Figure 2 presents the scheme of axle rolling using five tools. The most important ones are three identical rolls skewed in relation to the axis of the workpiece,

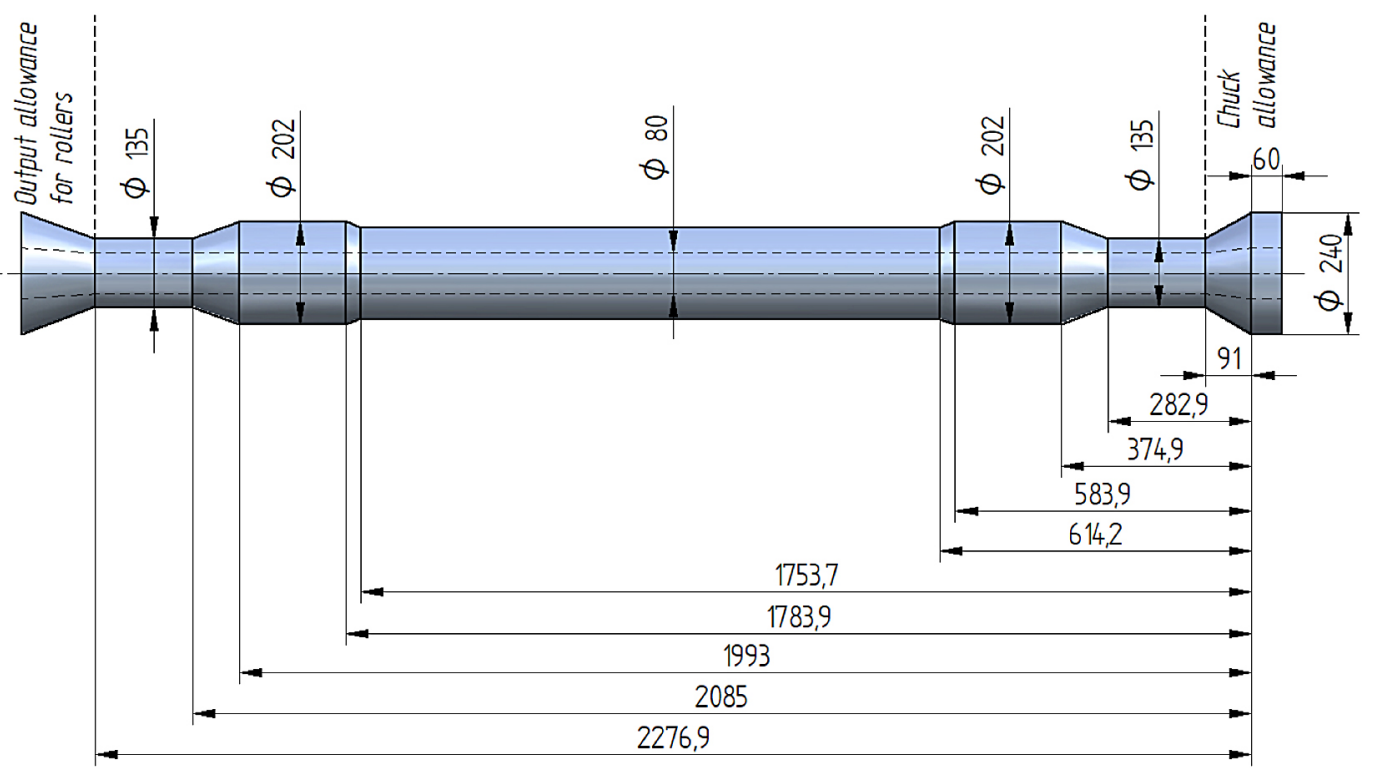

Fig. 1. Forging of a hollow axle with technological allowances, necessary for the process of skew rolling with a mandrel 


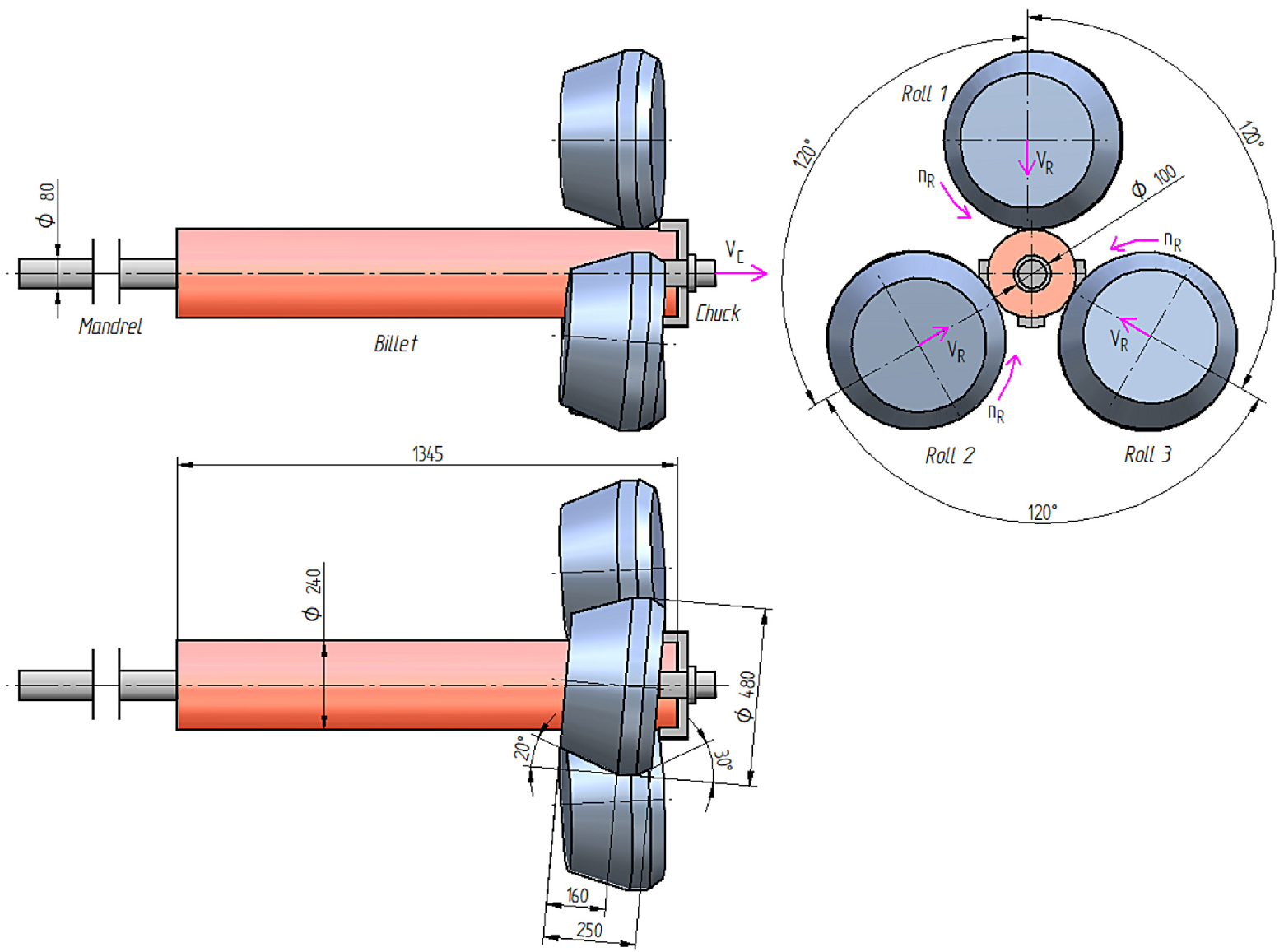

Fig. 2. Scheme of the process of skew rolling with a mandrel of a hollow axle; important dimensions given

rotating at the constant speed of $n_{R}$. Moreover, the tools can move in the radial direction at the speed of $v_{R}$, as a result of which the diameter of the rolled step might be changed. An important tool to this process is the chuck, moving at the speed of $v_{C}$ and controlling the axial dislocation of the workpiece. In order to obtain the assumed shape of the workpiece, it is necessary to properly establish $v_{C}$ and $v_{R}$. The last tool is a cylindrical mandrel longer than the formed axle, which aims to hinder radial material flow. The mandrel can rotate as well as move axially, but the movement is caused by the workpiece.

In order to prove the correctness of the presented forming concept a numerical model presented in Figure 3 was built in Simufact. Forming software. The shape and dimensions of the tools modelled as perfectly rigid bodies are in accordance with Figure 2. The billet is a sleeve with the outer diameter equal Ø240 mm, inner diameter $\varnothing 100 \mathrm{~mm}$ and length equal $1345 \mathrm{~mm}$.

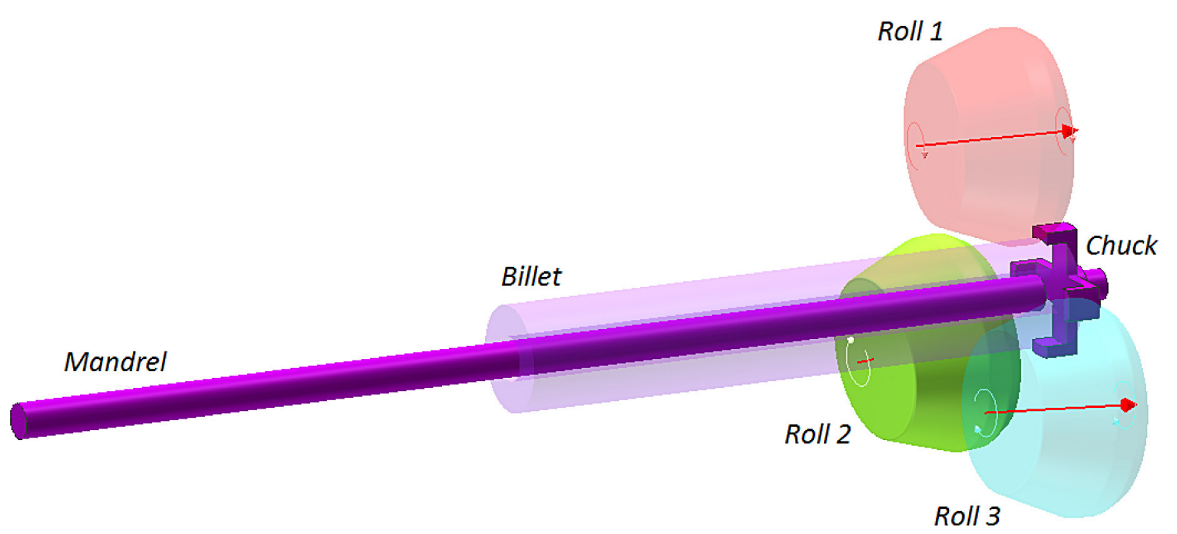

Fig. 3. Geometrical model of skew rolling of a hollow axle, perpared in Simufact.Forming v. 15 
It was assumed that the rolls rotate at the constant speed of $n_{R}=60 \mathrm{rpm}$ throughout the rolling process. Axial displacement of the chuck $v_{C}$ was also deemed to be constant. In Figure 4 it is compared to the radial speed $v_{R}$ of the rolls. With such kinematic parameters, the forming time for an axle equalled c.a. $45 \mathrm{~s}$.

The hollow axle is made of $42 \mathrm{CrMo} 4$ grade steel. The material model of this steel, taken from the library database of the employed software is described with the following equation :

$$
\sigma_{F}=4628.8 e^{-0.00345 T} \varepsilon^{(-0.00000509 T-0.03638)} e^{(-0.00000461 T-0.01944) / \varepsilon} \dot{\varepsilon}^{(0.0001893 T-0.04627)}
$$

where: $\sigma_{F}$ is flow stress, $\mathrm{MPa} ; \varepsilon$ is effective strain, $-; \dot{\varepsilon}$ is strain rate, $\mathrm{s}^{-1} ; \mathrm{T}$ is temperature, ${ }^{\circ} \mathrm{C}$.

For the simulation it was assumed that the billet was wholly heated to the temperature of $1180{ }^{\circ} \mathrm{C}$. The tool temperature was constant throughout the forming process and equalled $150{ }^{\circ} \mathrm{C}$ for the rolls and $500{ }^{\circ} \mathrm{C}$ for the chuck and the mandrel. Heat transfer coefficient between the tools and the material was assumed to be equal $10000 \mathrm{~W} / \mathrm{m}^{2} \mathrm{~K}$.

The friction was modelled using the Tresca model, expressed with the following equation:

$$
\tau=m k
$$

where: $\tau$ is shear stress on contact surface, $k$ is a shear yield stress $\left(k=\sigma_{F} / \sqrt{3}\right), m$ is friction factor (set equal to $m=0.8$ for rolls
[18] and $m=0.4$ for mandrel). The contact between the chuck and the workpiece was determined by a glued model.

The workpiece was modelled using hexahedral-type elements. The base size of these elements was assumed to be $16 \mathrm{~mm}$ in the unformed part and $8 \mathrm{~mm}$ in the formed area, which is well illustrated by Figure 5. During calculations, remeshing occurred when effective strain exceeded 0.4.

The described process of rolling a hollow axle was simulated in 22500 steps. The calculation time for a 32-core computer was 2 weeks. This indicates the complexity of the numerical simulation.

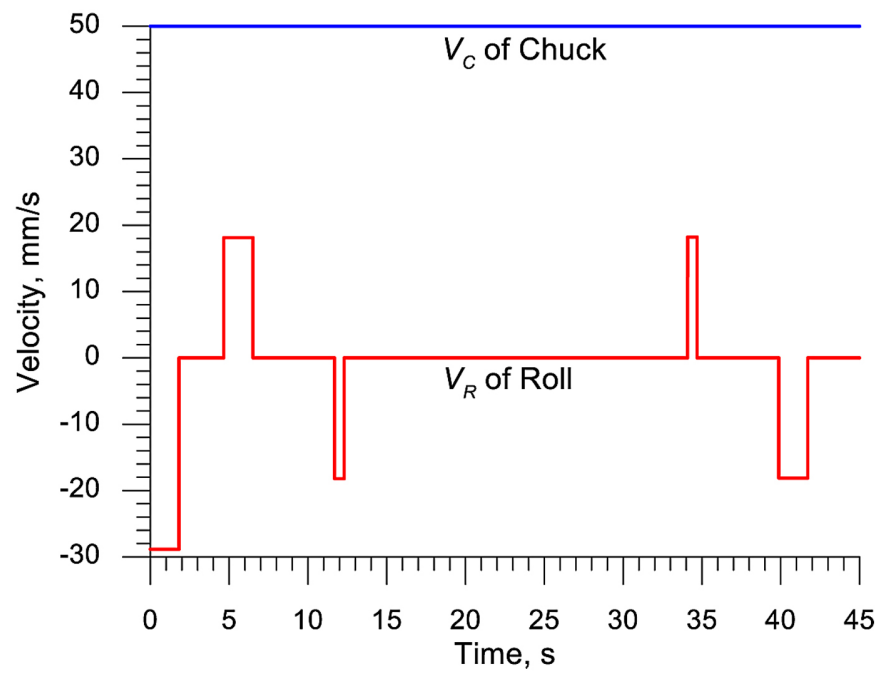

Fig. 4. Distributions of radial speed of the roll and the axial speed of the chuck during the process of skew rolling a hollow rail axle on a mandrel

Billet

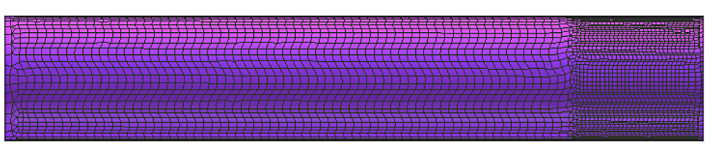

Rolled axle

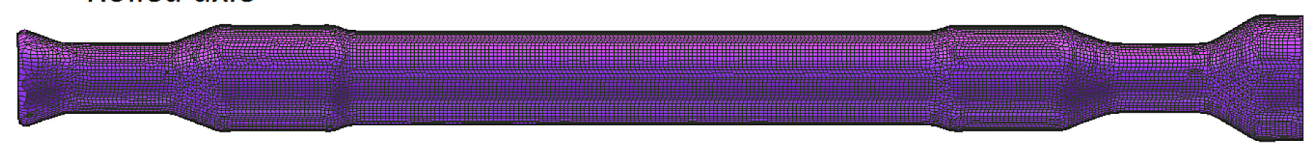

Fig. 5. View of the billet and the formed part, divided into hexahedral-type elements 


\section{OBTAINED RESULTS}

The numerical simulation was deemed a success. The progression of the rolling process was shown in Figure 6. At the initial forming phase, the radially moving rolls compress the material on the mandrel. As a result of friction forces the material is set in ambling motion both in axial and rotational direction. Along with the dislocation of the chuck, subsequent parts of the hollow axle are formed until its final shape.

Figure 7 presents a side and longitudinalsection view of the axle. It can be observed that the axial hole is cylindrical with $\varnothing 80 \mathrm{~mm}$ diameter. The figure also presents the distribution of effective strain. The material was plastically deformed throughout the entire volume of the axle due to the usage of a billet with the outer diameter $(\varnothing 240 \mathrm{~mm})$ significantly greater than the maximum diameter of the axle (Ø202 $\mathrm{mm})$. The deformations are placed annularly, with the greatest values located in the outer layers and the greatest in the inner ones. Such a distribution is caused by the rolls causing intensive material flow in the tangential direction. Such a distribution is typical for skew rolling processes [19].

The process of forming a hollow axle in accordance with the proposed concept is relatively long. One might therefore wonder if the material does not cool to such an extent that would hinder the forming process. Upon considering the temperature distributions shown in Figure 8, it can
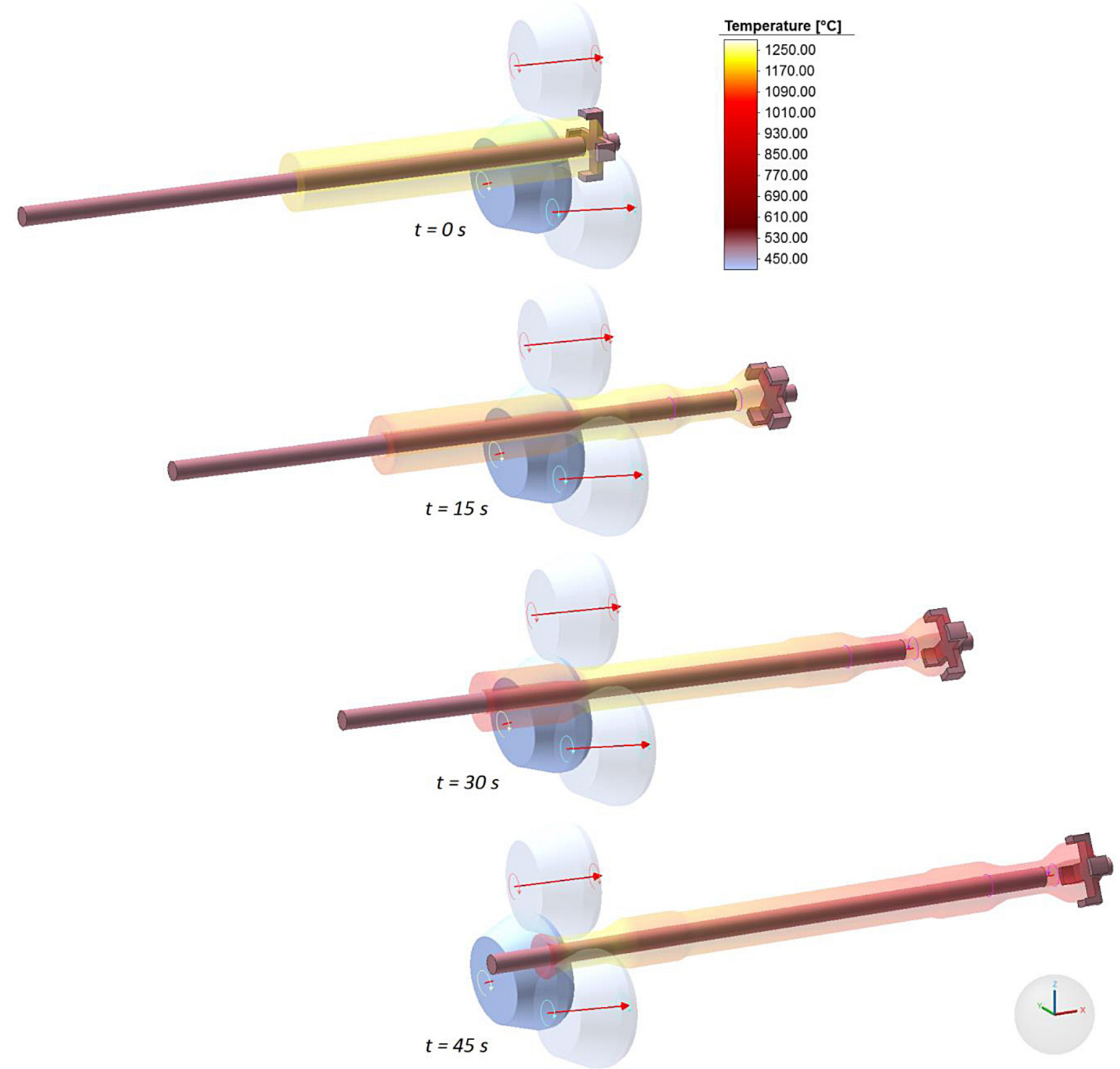

Fig. 6. Progression of the skew rolling process of a hollow axle on a mandrel, temperature distribution given (in ${ }^{\circ} \mathrm{C}$ ) 
be stated that such fear is unwarranted, since the highest temperature (exceeding even the billet temperature) is reached by the material of the end step opposite to the chuck. This step is formed in the last stage of the process and it seems that the material ought to be cooler as a result of heat being transferred to the environment. However, during forming significant amounts of heat are produced as a result of the work of plastic strain and the work of friction being converted into it. As a result, material temperature in the forming zone exceeds the billet temperature.

One of the limitations to the skew rolling processes is the occurrence of cracks inside the rolled parts $[20,21]$. The crack occurrence may be monitored by controlling the values of the so-called damage function. Figure 9 presents a distribution of such a function, calculated in accordance with the normalised Cockcroft-Latham criterion $[22,23]$. It is to be observed that the greatest values (reaching 2) of the function are located in the end steps, where the material is the most deformed. In order to prognosticate the risk of cracking occurrence it is necessary to know the value of critical damage, which is obtained in the calibrating test. It is important for the stress state in the calibrating test to be as similar as possible to the stress state of the analysed case of forming. In the case of three-roll skew rolling such a test is rotary compression of a disc in a channel [24]. Critical damage values for $42 \mathrm{CrMo} 4$ grade steel, determined in the course of the presented test, were shown in study [11]. For $1180{ }^{\circ} \mathrm{C}$ the critical damage value equals 3.2 and is significantly

Effective plastic strain

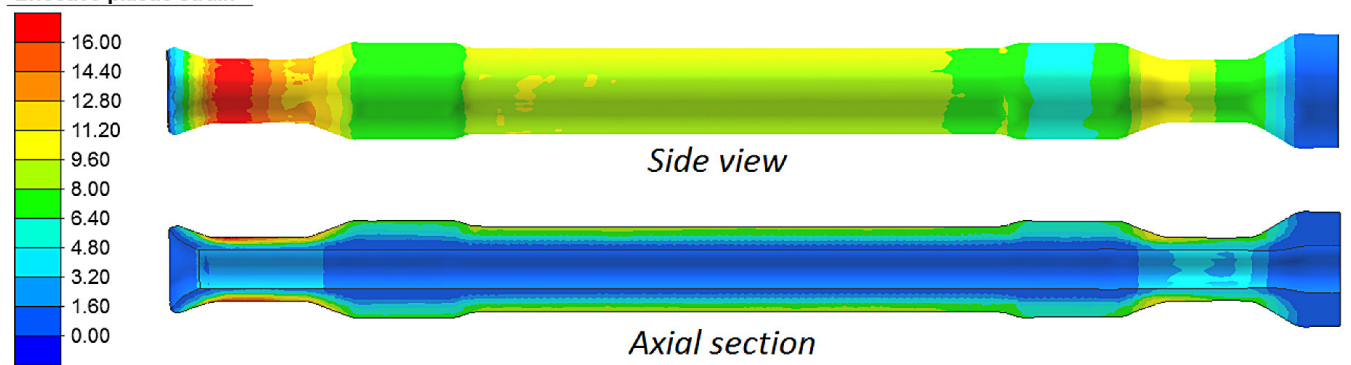

Fig. 7. Distributions of effective strain in a rolled hollow axle

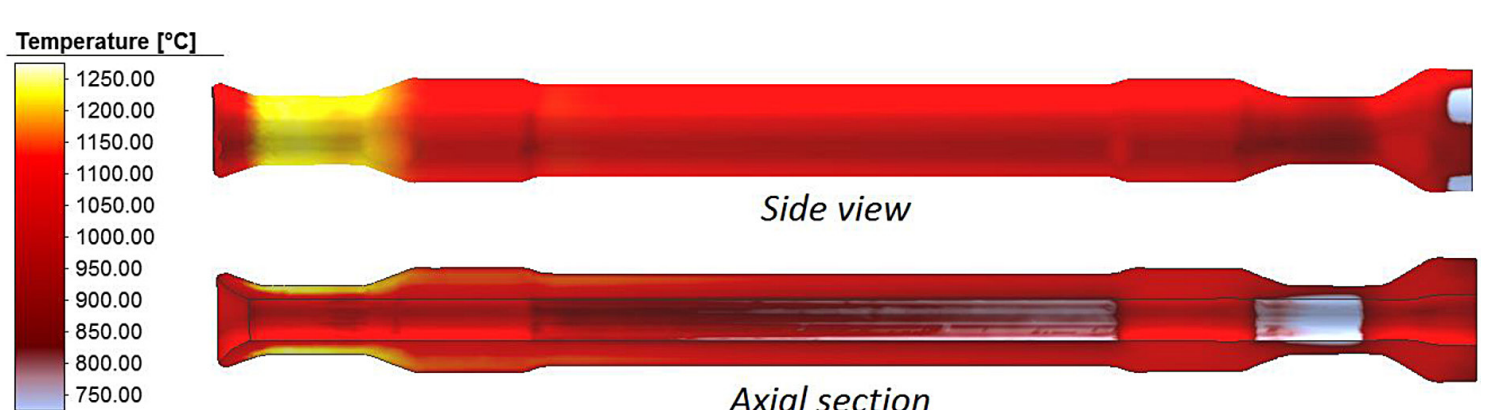

Axial section

Fig. 8. Distributions of temperature in a rolled hollow axle
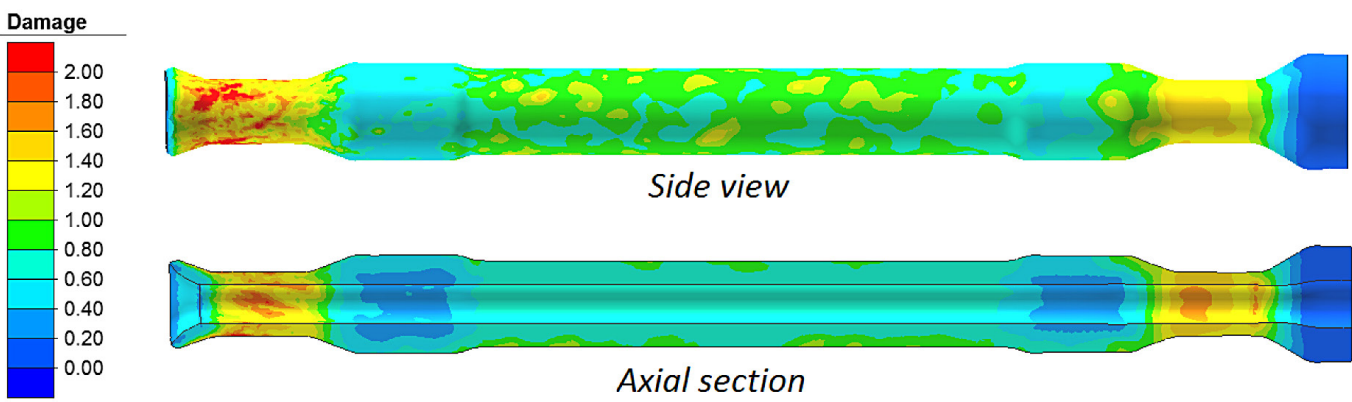

Side view

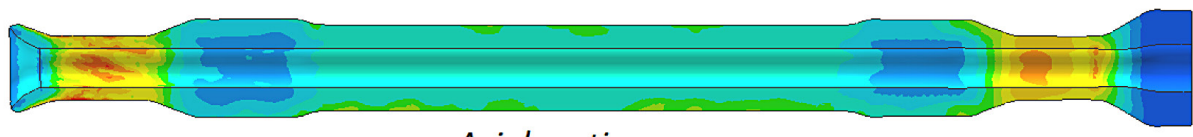

Axial section

Fig. 9. Distributions of the damage function according to normalized Cockcroft-Latham criterion in a rolled hollow axle 
greater than the maximum values observed in the analysed rolling process. Therefore it can be stated that in the analysed process of forming a hollow axle cracking should not occur.

Furthermore, numerical simulation also provided information on force parameters in the designed forming process. Figure 10 presents distributions of forces acting on the roll in the radial direction and on the chuck in the axial direction. The greatest forces on the roll occurred during forming of side steps, when the reduction of the billet diameter was the most intensive. These forces reached values to $1000 \mathrm{kN}$. The axial force on the chuck reached maximum values (up to $300 \mathrm{kN}$ ) during the forming process of the central step of the axle. During forming of side steps the values of this force were smaller due to the axial material flow being more intensive. Considering the dimensions of the workpiece, the obtained maximum values of the forming forces ought to be deemed relatively small, which should result in a light construction of the industrial rolling mill.

Figure 11 presents a distribution of torque on a roll. This distribution is identical to the distribution of radial force. The maximum value of torque occurs during forming of side steps, where it reaches $50 \mathrm{kNm}$. The power of the engine acting on a single roll equals $314 \mathrm{~kW}$. It can therefore be assumed

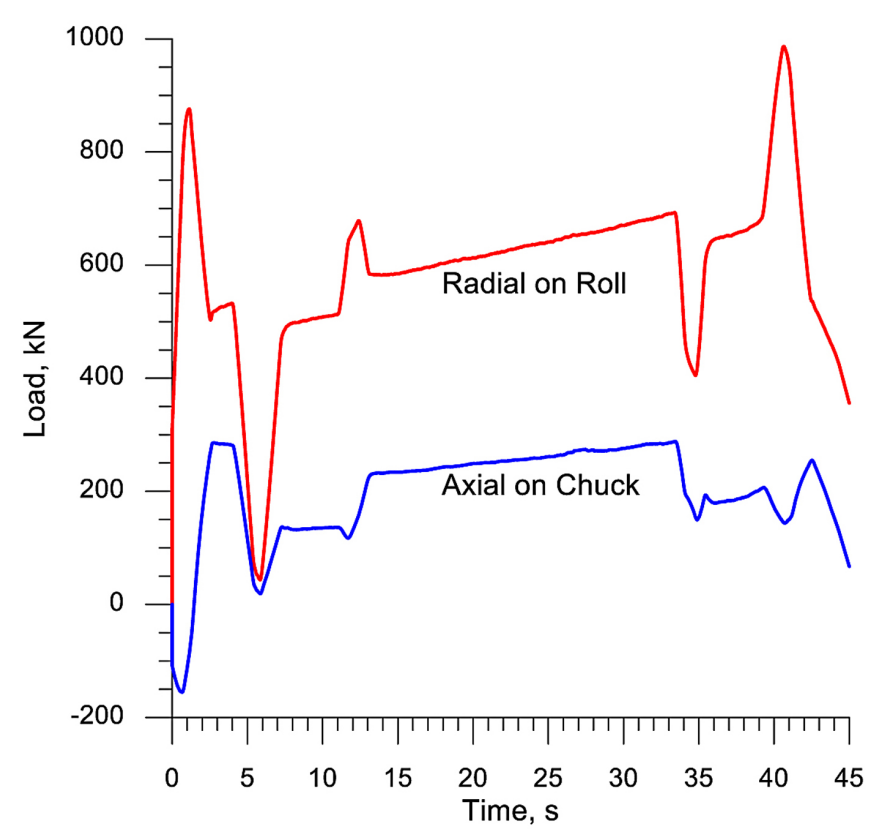

Fig. 10. Distributions of the forces acting on the roll and chuck during the process of rolling hollow rail axle on a mandrel

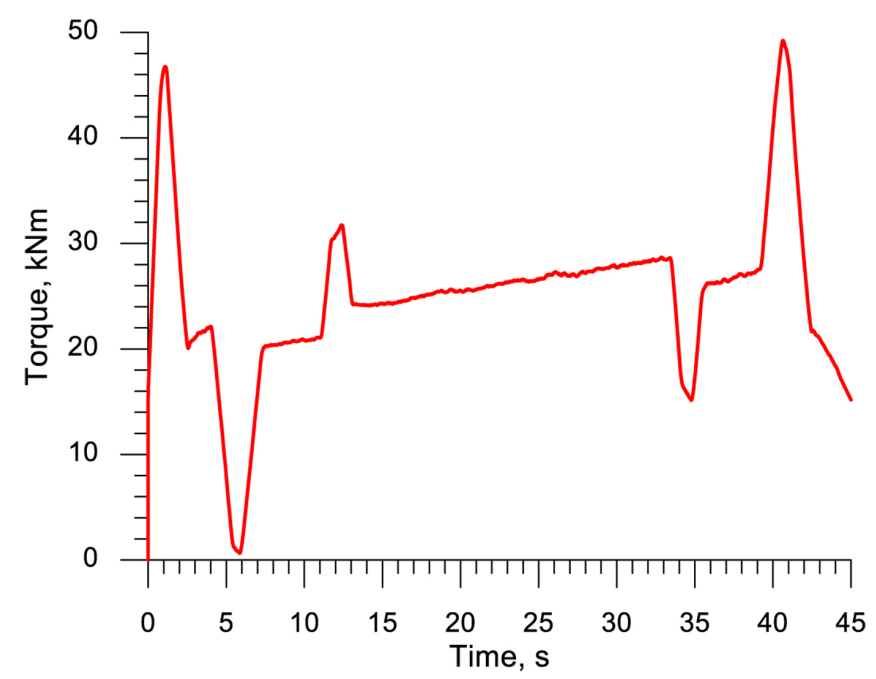

Fig. 11. Distribution of torque for a roll in the process of skew rolling of a hollow axle on a mandrel 
that the industrial rolling mill used for manufacturing hollow axles on a moving mandrel ought to be powered by three engines with $350 \mathrm{~kW}$ each. Due to the fact that the maximum values of the torque appear temporarily, it is possible to decrease the engine power to $250 \mathrm{~kW}$ upon using flywheels.

\section{CONCLUSIONS}

On the basis of the analysis performed it was stated that the method of CNC skew rolling may be used for manufacturing hollow rail axles with a cylindrical hole of constant diameter. The proper progression of the forming process depends on the usage of sleeve-shaped billet with the outer diameter exceeding the maximum diameter of the rolled part, whereas the inner diameter is greater than the diameter of the hole. During rolling, the outer shape of the axle is formed by three rolls, whereas the diameter of the hole is determined by a movable cylindrical mandrel. The operation of the aforementioned tools (rolls and mandrel) causes the material to intensively flow in the tangential direction, which results in an annular distribution of effective strain in the workpiece. The greatest values of strain can be observed in the outer layers of the axle, which is caused by friction forces on the roll-workpiece contact surface. Despite a relatively long forming time (c.a. $45 \mathrm{~s}$ ) the material temperature remains in the range appropriate for hot working. This phenomenon is caused by the fact that the heat transported to the tools and environment is being compensated by the heat generated as a result of the work of friction and plastic strain. The hollow axle manufactured with the proposed method has a correct shape and is free of inner cracks. A characteristic trait of the rolling process is relatively low values of force parameter allowing one to manufacture hollow rail axles using a rolling mill with a light structure.

\section{REFERENCES}

1. Tomczak J. 2016. Studium procesów obciskania obrotowego odkuwek drążonych. Wyd. Politechniki Lubelskiej, Lublin.

2. Romanenko V.P., Stepanov P.P., Kriskovich S.M. 2017. Production of Hollow Railroad Axles by Screw Piercing and Radial Forging. Metalurgist, 61(9-10), 873-877.

3. Shu X., Wei X., Li C. Hu Z. 2010. The Influence Rules of Stress about Technical Parameters on Syn- chronous Rolling Railway Axis with Multi-wedge Cross-wedge Rolling. Applied Mechanics and Materials, 37-38, 1482-1488.

4. Pater Z., Tomczak J. 2018. A New Cross Wedge Rolling Process for Producing Rail Axles. MATEC Web of Conferences. 1090:e11006.

5. Pater Z. 2020. Numerical analysis of the cross-wedge rolling process of a railway axle. Mechanik, 2, 18-21.

6. Hu B., Shu X., Yu P., Peng W. 2014. The Strain Analysis at the Broadening Stage of the Hollow Railway Axle by Multi-wedge Cross Wedge Rolling. Applied Mechanics and Materials, 494-495, 457-460.

7. Sun B., Zeng X., Shu X., Peng W., Sun P. 2012. Feasibility Study on Forming Hollow Axle with Multiwedge Synchrostep by Cross Wedge Rolling. Applied Mechanics and Materials, 201-202, 673-674.

8. Zheng S., Shu X., Han S., Yu P. 2019. Mechanism and force-energy parameters of a hollow shaft's multiwedge synchrostep cross-wedge rolling. Journal of Mechanical Science and Technology, 33(5), 1-10.

9. Peng W., Zheng S., Chiu Y., Shu X., Zhan L. 2016. Multi-wedge Cross Wedge Rolling Process of 42CrMo4 Large and Long Hollow Shaft. Rare Materials and Engineering, 45(4), 836-842.

10. Pater Z., Lis K., Walczuk-Gągała P. 2020. Numerical Analysis of the Cross-Wedge of Hollow Rail Axle. Advances in Science and Technology Research Journal, 14(1), 145-153.

11. Pater Z., Tomczak J., Bulzak T., Wójcik Ł. 2021. Conception of a Three Roll Cross Rolling Process of Hollow Rail Axles. ISIJ International, 61(3), 895-901.

12. Pater Z., Tomczak J., Bulzak T. 2015. Numerical analysis of the skew rolling process for rail axles. Archives of Metallurgy and Materials, 60(1), 415-418.

13. Xu C., Shu X. 2018. Influence of process parameters on the forming mechanics parameters of the three-roll skew rolling forming of the railway hollow shaft with 1:5. Metalurgija, 57(3), 153-156.

14. Pater Z., Tomczak J., Lis K., Bulzak T., Shu X. 2020. Forming of rail car axles in CNC skew rolling mill. Archives of Civil and Mechanical Engineering. 20:e69.

15. Pater Z., Tomczak J., Bulzak T. 2020. Problems of forming stepped axles and shafts in a 3-roller skew rolling mill. Journal of Materials Research and Technology, 9(5), 10434-10446.

16. Wang J.T., Shu X.D., Zhang S. 2020. Effect of process parameters on average grain size and microscopic uniformity of the three-roll skew rolling forming of the railway hollow shaft. Metalurgija, 59(1), 47-50.

17. Pater Z. 2020. A Comparative Analysis of Forming Railway Axles in 3- and 4-Roll Rolling Mills. Materials, 13:e3084.

18. Murillo-Marrodan A., Garcia E., Cortes F. 2018. A study of friction model performance in a skew 
rolling process numerical simulation. International Journal of Simulation Modeling, 17(4), 569-582.

19. Pater Z. 2014. Cross Wedge Rolling. In: Button ST, Ed. Comprehensive Materials Processing, Elsevier Ltd, 3, 211-279.

20. Yamane K., Shimoda K., Kuroda K., Kajikawa S., Kuboki T. 2021. A new ductile fracture criterion for skew rolling and its application to evaluate the effect of number of rolls. Journal of Materials Processing Technology, 291:e116989.

21. Pater Z., Tomczak J., Bulzak T., Wojcik Ł., Skripalenko M.M. 2021. Prediction of ductile fracture in skew rolling processes. International Journal of Machine Tools and Manufacture, 163:e103706.

22. Cockroft M.G., Latham D.J. 1968. Ductility and the workability of metals. Journal of the Institute of Metals. 96, 33-39.

23. Oh S.I., Chen C.C., Kobayashi S. 1979. Ductile fracture in axisymmetric extrusion and drawing. Part II Workability in extrusion and drawing. Journal of Industrial Engineering International, 101(1), 36-44.

24. Pater Z., Tomczak J., Bulzak T. 2020. Rotary compression as a new calibration test for prediction of a critical damage value. Journal of Materials Research and Technology, 9(3), 5487-5498. 